\title{
Yield response and optimal allocation of irrigation water under actual and simulated climate change scenarios in a southern Italy district
}

\author{
Pietro Rubino, Matteo Stelluti, Anna Maria Stellacci, Elena Armenise, Adelaide Ciccarese, \\ Mohamed Houssemeddine Sellami \\ Dipartimento di Scienze Agro-Ambientali e Territoriali, Università di Bari, Italy
}

\begin{abstract}
The potential effect of climate change on the optimal allocation of irrigation water was investigated for a Southern Italy district. The study was carried out on 5 representative crops (grapevine, olive, sugar beet, processing tomato, asparagus), considering six simulated climate change conditions, corresponding to three 30 -year periods (2011-2040; 2041-2070; 2071-2100) for two greenhouse gas emission schemes proposed by IPCC (A2 and B1), plus the current climatic condition. The framework adopted was based on: i) the modeling of crop yield response for increasing levels of water supply, under current and future climatic conditions, through a non-linear regression equation and ii) the definition of the best water allocation by means of a mathematical optimization model written in the General Algebraic Modeling System (GAMS). Total irrigation water (TIW) volume was allowed to vary from a low total supply $10,000 \mathrm{~m}^{3}$ to $7,000,000 \mathrm{~m}^{3}$, whilst a fixed surface, corresponding to that currently occupied in the studied district, was assigned to each crop. The economic return was studied in terms of Value of Production less the fixed and variable irrigation costs $\left(\mathrm{VP}_{\text {lic }}\right)$. The TIW volume that maximized the VPlic of the whole district surface under the current climatic condition was $5,697,861 \mathrm{~m}^{3}$. The total volume was partitioned among the five crops as a function of the surface occupied: grapevine $>$ olive $>$ processing tomato $>$ asparagus $>$ sugar beet. Nevertheless, grapevine and olive received
\end{abstract}

Correspondence: Dr. Pietro Rubino, Università di Bari, Dipartimento di Scienze Agro-Ambientali e Territoriali, via Orabona 4, 70126, Bari, Italy.

Tel. +39.080 .5443032 - Fax: +39.080 .5442976 .

E-mail: pietro.rubino@agr.uniba.it

Key words: GAMS, irrigation water partitioning, mathematical optimization models, simulated climatic conditions.

Acknowledgements: this research was funded by CLIMESCO Evolution of cropping systems as affected by climate change project, contract n. 285, 20/02/2006 (Ministry for Education, University and Research).

Received for publication: 21 April 2011.

Accepted for publication: 24 November 2011.

(C) Copyright P. Rubino et al., 2012

Licensee PAGEPress, Italy

Italian Journal of Agronomy 2012; 7:e18

doi:10.4081/ija.2012.e18

This article is distributed under the terms of the Creative Commons Attribution Noncommercial License (by-nc 3.0) which permits any noncommercial use, distribution, and reproduction in any medium, provided the original author(s) and source are credited. seasonal volumes corresponding only to $59 \%$ and $50 \%$ of total irrigation water requirements. On the contrary, processing tomato and asparagus received seasonal water volumes close to those fully satisfying irrigation water requirements ( $100 \%$ and $85 \%$ ETc). Future climatic conditions slightly differed from the current one for the expected optimal allocation. Under water shortage conditions $\left(160,000 \mathrm{~m}^{3}\right)$ the whole irrigation water was allocated to the horticultural crops. Forecasted growing season features varied to a different extent in relation to crop and scenario considered with the more intense changes observed for $\mathrm{A} 2$ and olive.

\section{Introduction}

Freshwater is a finite resource and the development of additional supplies for human uses is increasingly limited by economic and ecological constraints. About $70 \%$ of the total water resources is used in agriculture (FA0, 2006) and is mainly assigned to irrigation which has a crucial role in meeting the world food and fiber needs (Howell, 2001). This amount, greater in the arid and semi-arid environments and in the developing countries, is already inadequate to fulfill the actual irrigation needs and is expected to decrease in the next few years due to the human population and affluence growth and to the consequent intensifying competition with domestic, recreational and industrial uses.

In addition, high uncertainty on the future water supply to agriculture is generated by the predictions about climate changes. According to the Fourth Assessment Report (AR4) of the United Nations Intergovernmental Panel on Climate Change (IPCC) warming of the climate system is unequivocal, as evident from observations of increases in global average air and ocean temperatures, widespread melting of snow and ice and rising global average sea level (IPCC, 2007). The main expected impacts of global warming will be represented by higher and more variable temperatures, changes in precipitation patterns (lower and more erratic rainfall) and higher frequency of extreme events. With particular regard to the Mediterranean environment, according to climate models, an increase in winter temperature combined with changes in rainfall amount and distribution would be expected (Mimi and Jamous, 2010).

If the predictions about climatic changes occurred, the increased frequency and severity of droughts would further decrease irrigation water supplies (Hsiao et al., 2007). In addition, climate changes are expected to affect plant growth and agricultural production (Schlenker et al., 2007) as a consequence of the effect of temperature on plant phenology, and in turn crop cycle length, as well as of $\mathrm{CO}_{2}$ concentration on carbon assimilation and water use efficiency (Olesen and Bindi, 2002; Lovelli et al., 2009). Nevertheless, the simulation of crop growth and water requirements is complicated by the high uncertainty both on the future variability of climatic parameters and on the com- 
bined effect of their variation on plant response.

To face the great challenge of increasing water supply to agriculture, a key strategy consists in improving the overall water use efficiency (WUE) which is still relatively low. Given the wide range of factors affecting water loss throughout the system of water use and management, the improvement of WUE requires a comprehensive and systematic approach. Hsiao et al. (2007) considered the overall efficiency as a chain of single multiplicative components. This quantitative framework is very useful as it allows to examine the current level of each efficiency along the entire pathway of agricultural water use, analyze the critical steps, quantifying their impact on the overall efficiency, and ultimately assess the potential achievable improvements. In this context, one of the most crucial steps is represented by the optimal allocation of the available water resources both at on-farm or at irrigation district level. The optimization of water allocation consists in partitioning the water resource among different crops grown in the same environment in order to maximize the profit. This aspect assumes a crucial importance, as the economic profitability of water used for irrigation is often low in comparison to the competing uses (Reca et al., 2001). In general, the optimization of resources allocation, in order to obtain the maximal benefit, requires the knowledge of the crop yield response to the studied factor, expressed in economical terms, and the identification of the cost necessary to achieve each fractional yield increase, i.e. the marginal cost (Hsiao et al., 2007). In addition, it requires the use of mathematical models of optimization to solve complex systems of equations, particularly when the number of unknowns is higher than the constraint relations.

Many researches have been carried out to define the optimal water and land allocation among several crops (Al-Weshah, 2000; Gorantiwar and Smout, 2006; Onta et al., 1995; Paul et al., 2000; Rana et al., 2004; Reca et al., 2001; Rubino et al., 2008; Sahoo et al., 2001; Shangguan et al., 2002). Among them, a flexible framework, performing the optimization process across a wide range of water availability, was proposed (Rubino et al., 2008) and then successfully tested on herbaceous and horticultural crops in a Mediterranean environment. The framework is based on i) the modeling of crop yield response for increasing levels of water supply through a non linear regression equation and ii) the definition of the best resource allocation by means of a non linear mathematical optimization model. This flexible approach can be used across different crop, climate and socio-economic scenarios, therefore, may result extremely effective to study the impact of climatic changes on optimal resources allocation.

The aim of this study was to investigate the potential effect of climate change on crop yield response and on the optimal allocation of water supplies among crops at district level using the framework adopted by Rubino et al. (2008). To this end, a southern Italy irrigation district was considered as a case study and the crop yield response patterns under the current climatic condition were compared to those obtained under future simulated scenarios based on the A2 and B1 greenhouse gas emission schemes proposed by the IPCC (2000).

\section{Materials and methods}

\section{Site and climate change scenarios description}

The study area was the district 4 of the Sinistra Ofanto irrigation scheme included in the Consortium of Bonifica della Capitanata (Apulia region, southern Italy). This Consortium is the most important in the Apulia region, both in terms of irrigated surface and crop water requirements, and is one of the major consortia in the whole Mediterranean area (Lamaddalena et al., 2004).

The district extends on a total surface of 3256 ha and includes 2340 ha of irrigated crops and 916 ha of dry arable crops which account for
$71.9 \%$ and $28.1 \%$ of the total district area respectively. The irrigated area is mainly occupied by vineyards and olive groves $(79.1 \%$ and $12.0 \%$ of the total irrigated surface), followed by orchards, arable and horticultural land (Table 1). Five crops were selected for this study as the most representative of the area: grapevine, olive, sugar beet, processing tomato and asparagus. Fruit crops were excluded because not suitable data were found in literature to describe their yield response to irrigation water.

The study considered six simulated climate change conditions corresponding to three thirty-year periods (2011-2040; 2041-2070; 20712100) for each selected greenhouse gas emission scheme (A2 and B1), plus the current climatic condition.

A2 and B1 schemes were chosen as they envisage contrasting climate evolution as a consequence of the key driving forces, i.e. demographic, social and economic development and technological change (IPCC, 2000). Specifically, the A2 scenario family describes a very heterogeneous world, where self-reliance and preservation of local identities prevail. Economic development is primarily regionally oriented and per capita economic growth and technological change are more fragmented and slower than in other scenarios. This scenario predicts the deepest climatic changes. The B1 scenario family describes instead a convergent world with emphasis on global solutions to economic, social, and environmental sustainability, including improved equity, but without additional climate initiatives. Although the B1 scenario assumes the less intensive climate changes, it forecasts $\mathrm{CO}_{2}$ concentrations of $550 \mathrm{ppm}$ by the end of the century, i.e. two times the pre-industrial $\mathrm{CO}_{2}$ levels $(280 \mathrm{ppm})$. The current climatic condition was described using 53-year time series of daily data of minimum and maximum air temperature, rainfall and global solar radiation, collected at the agro-meteorological station of the CRA-SCA podere 124 (Foggia, $41^{\circ} 30^{\prime} \mathrm{N}, 15^{\circ} 30^{\prime} \mathrm{E}$, altitude $90 \mathrm{~m}$ ) located nearby the study area. The future climatic time series, referring to the following three thirty-year periods: 2011-2040; 2041-2070; 2071-2100, for each selected climate change scenario, were generated applying a statistical downscaling procedure as described by Pizzigalli et al. (2012).

\section{Optimal water allocation framework}

The framework adopted to simulate the crop yield response to irrigation water and to assess the optimal water allocation at district level, under the different climatic conditions compared, encompassed the following steps: i) investigation of the mathematical relationship between crop yield and irrigation water by means of the modified Mitscherlich equation (Giardini and Borin, 1985), using data from literature review; ii) quantification of irrigation water requirements under the current condition and climate change scenarios and computation of the yield to water response parameters; iii) definition of the total irrigation water volume maximizing the district economic return and assessment of the optimal water partitioning among the

Table 1. Partitioning of the irrigation surface in District 4 of the Sinistra Ofanto irrigation scheme.

\begin{tabular}{|c|c|c|}
\hline \multirow[t]{2}{*}{ Crop } & \multicolumn{2}{|c|}{ Surface } \\
\hline & ha & $\%$ \\
\hline Grapevine & 1850 & 79.1 \\
\hline Olive & 280 & 12.0 \\
\hline Fruit trees & 75 & 3.2 \\
\hline Asparagus & 55 & 2.4 \\
\hline Processing tomato & 40 & 1.7 \\
\hline Sugar beet & 40 & 1.7 \\
\hline Total irrigated surface & 2340 & 100 \\
\hline
\end{tabular}


irrigated crops through a non linear mathematical optimization model written in the General Algebraic Modeling System (GAMS).

The yield response to increasing levels of water supply, for each selected crop, was investigated by fitting experimental data from literature review through the modified Mitscherlich equation, after converting the seasonal irrigation water volumes in percentage of the maximum evapotranspiration (ETc) less the effective rainfall. This standardization of water consumption allowed taking into account inter-annual weather variability and comparing results obtained under different experimental conditions.

The modified Mitscherlich yield-water supply function was selected among statistical non linear regression equations because its parameters are characterised by a clear agronomic and biologic meaning. This equation can include three (eq. 1) or four (eq. 2) parameters. When four parameters are considered, the equation also accounts for the decreasing yield expected at levels of the examined factor (in this case the seasonal irrigation water volume) exceeding the optimal value.

The equations are:

$$
\begin{gathered}
y=A\left[1-10^{-c(b+x)}\right] /\left[1+10^{1-c(b+x)}\right] \\
y=A\left[1-10^{-c(b+x)}\right] \cdot\left[10^{-K(b+x) 2}\right] /\left[1+10^{1-c(b+x)}\right](2)
\end{gathered}
$$

where: $y$ is the yield, in $\mathrm{tha}^{-1} ; A$ is the maximum potential yield ( $\mathrm{t}$ $\mathrm{ha}^{-1}$ ); $c$ is the coefficient accounting for the rate of achieving the maximum yield (ha $\mathrm{m}^{-3}$ ); $K$ is the coefficient accounting for the rate at which yield decreases after the maximum value is reached [ (ha $\left.\left.\mathrm{m}^{-3}\right)^{2}\right] ; b$ is an estimate of the volume of water available for the crop under natural conditions, i.e. the sum of soil moisture at sowing or transplanting and effective rainfall recorded over the crop cycle $\left(\mathrm{m}^{3}\right.$ $\left.\mathrm{ha}^{-1}\right) ; x$ represents the seasonal irrigation water volume supplied under the specific experimental conditions $\left(\mathrm{m}^{3} \mathrm{ha}^{-1}\right)$.

The three parameters Mitscherlich equation was fitted to grape, olive and sugar beet. The four parameters equation was instead applied to processing tomato and asparagus because the literature data available for these crops accounted also for the decreasing yield response associated with seasonal irrigation volumes higher than the optimal.

The quantification of crop irrigation water requirements under current condition and future scenarios required the assessment of crop growing season parameters: beginning of the season (date of sowing/transplanting for herbaceous crops, bud break for perennial crops); timing and duration of phenological stages; total length of the growing season. Phenology is the most important attribute involved in the yield assessment. For this reason studying the effect of warming climate on phenological development is a key-aspect in the assessment of the impact of climate change on agriculture (Moriondo and Bindi, 2007). The reference starting dates under climate change scenarios (bud break for grapevine and olive; recovery from transplanting for processing tomato; beginning of commercial maturity for asparagus) were defined using the simple moving average (20 days) of the daily mean temperatures. Simple moving average ranks among the most popular techniques for processing of climatic time series as it smoothes short term fluctuations and highlights long-term trends or cycles. In the present study, the reference starting date for future scenarios occurred when the simple moving average computed with the meteorological data of the hypothesized scenario equaled the one computed for the current condition. For autumnal sugar beet the sowing date was kept constant (November ${ }^{\text {st }}$ ) for both the current and the simulated climatic conditions.

The timing of phenological stages and their duration were defined by the growing degree days accumulation technique, in order to take into account the effect of temperature on plant phenological development. Growing degree days and moving average were chosen for the assessment of crop growing season parameters as they are both generally adopted methods for the simulation of crop phenology and yield in agroclimatic modeling (Ben Mechlia and Carroll, 1989).

After fixing crop cycle parameters for each species and climatic condition, daily ETo was computed using Hargreaves and PriestlyTaylor equations (Hargreaves and Samani, 1985; Priestley and Taylor, 1972). Daily maximum crop evapotranspiration (ETc) was subsequently obtained using the crop coefficients reported in Table 2 (ETc $=$ ETo $\bullet \mathrm{kc}$ ). Irrigation water requirements, expressed as seasonal irrigation water volumes $\left(\mathrm{m}^{3} \mathrm{ha}^{-1}\right)$, were then calculated by subtracting effective rainfall to the total crop water requirements.

Yield data, kept constant for each crop under different climatic conditions, were plotted against seasonal irrigation water volumes $\left(\mathrm{m}^{3}\right.$ $\mathrm{ha}^{-1}$ ), corresponding to increasing fractions of irrigation water requirements, and fitted through the modified Mitscherlich equation. As the optimal allocation of water resources is based on economic efficiency criteria, the $A$ values (maximum yield estimated by the Mitscherlich function, $\mathrm{t} \mathrm{ha}^{-1}$ ) were converted into values of production (VP, euro ha ${ }^{-1}$ ), considering the current market prices of the agriculture products. The expression of $A$ in economical terms does not modify either the value of the other parameters $(b, c$ and $K)$ or their agronomical meaning.

The Mitscherlich equation parameters $(A, b, c, k)$ were then used as input into the non linear mathematical optimization model. The GAMS (Brooke et al., 1982) was used to solve the optimization problem. GAMS was chosen as it is a high-level modeling system for mathematical programming and optimization. It consists of a language compiler and a stable of integrated high-performance solvers. The system is tailored for complex, large scale modeling applications, and allows to build large maintainable models that can be adapted quickly to new situations (http://www.gams.com). Mathematical modelling systems are necessary when the allocation of the yield factor refers to more than one crop and the costs are described by step functions. In addition, they are required when several levels of the yield factor are contemporaneously tested.

In the present study, the optimization process aimed to define the total irrigation water (TIW) volume which maximized the economic return of the district and its optimal partitioning among the selected crops. In addition, as the optimal water allocation varies with the total water supply, it was also investigated the optimal water distribution

Table 2. Monthly crop coefficients for district representative crops.

\begin{tabular}{lccccc} 
Grapevine & Olive & $\begin{array}{c}\text { Processing } \\
\text { tomato }\end{array}$ & Asparagus & $\begin{array}{c}\text { Sugar } \\
\text { beet }\end{array}$ \\
January & 0.4 & 0.5 & 0.4 & 0.15 & 0.6 \\
February & 0.4 & 0.5 & 0.4 & 0.15 & 0.75 \\
\hline March & 0.4 & 0.5 & 0.4 & 0.15 & 0.85 \\
April & 0.5 & 0.5 & 0.4 & 0.15 & 1 \\
\hline May & 0.6 & 0.5 & 0.6 & 0.15 & 1.1 \\
June & 0.7 & 0.5 & 0.9 & 0.5 & 1.1 \\
\hline July & 0.75 & 0.5 & 1.1 & 0.9 & 0.4 \\
August & 0.75 & 0.5 & 0.8 & 0.9 & 0.4 \\
\hline September & 0.4 & 0.5 & 0.4 & 0.9 & 0.4 \\
October & 0.4 & 0.5 & 0.4 & 0.2 & 0.4 \\
\hline November & 0.4 & 0.5 & 0.4 & 0.2 & 0.4 \\
December & 0.4 & 0.5 & 0.4 & 0.2 & 0.5 \\
\hline
\end{tabular}


for each TIW volume considered. The maximization of the economic return was studied in terms of value of production less the fixed and variable irrigation costs $\left(\mathrm{VP}_{\text {lic }}\right)$. This choice was done to focus the attention on the relationship between yield and irrigation volume, when all the other parameters are fixed. For this reason, the other elements of the system (variation of the land allocated to each crop, fixed and variable costs such as fertilizer, labor, and so on) were not investigated, and water resource consumption was the only condition imposed. Although this approach represents a simplification of the system, and the use of other costs would probably furnish more realistic results, this choice does not interfere with the validity of the modelling approach, which can be adapted to any specific situation.

The independent, or decision, variables were the seasonal irrigation volumes applied to each crop within each total irrigation water volume (TIW) considered. As five crops were selected (olive, grapevine, processing tomato, sugar beet, asparagus), decision variables were 5 dimensions vectors.

A fixed surface was instead allocated to each crop, corresponding to that currently occupied in district 4 of the Consortium of Bonifica della Capitanata, as previously indicated in Table 1. TIW volumes were imposed to vary from a low total supply $\left(10,000 \mathrm{~m}^{3}\right)$ to an amount higher than the one required to fully satisfy irrigation water requirements for the entire district surface $\left(7,000,000 \mathrm{~m}^{3}\right)$. This allowed to study optimal water allocation also under shortage conditions.

To simplify the modelling process, the components of the variable irrigation volume were forced to assume only discrete values. Classes were obtained by dividing the entire range into $10,000 \mathrm{~m}^{3}$ intervals. Within each class, water, i.e. the seasonal irrigation volume, was instead allowed to assume any continuous and positive real value for each crop. The computation was then reiterated for each class. The modelling problem required the inclusion of physical and economic constraints. The physical constraint imposed that the sum of the water volumes allocated to the selected crops within each class did not exceed the TIW volume. The economic constraints were instead related to the modelling of the binary tariff system adopted by the Consortium, which quantifies the water price as a function of the total volume used per unit surface. These constraints were modelled by imposing that water price changed when a volume higher than $2000 \mathrm{~m}^{3} \mathrm{ha}^{-1}$ was used (first constraint) and when the limit of 3000 $\mathrm{m}^{3} \mathrm{ha}^{-1}$ was overcome (second constraint). The two economic constraints led to the definition of three irrigation cost classes.

The objective function was written in the program as:

$$
Z=V P_{\text {lic }}=A_{p} \Sigma_{p} V P_{p}-A_{p} \Sigma_{p} C_{\text {fixed }}-A_{p} \Sigma\left(C_{\text {var }}\right)
$$

where, $\mathrm{VP}_{\text {lic }}$ was the Value of Production less the irrigation costs; $\mathrm{VP}_{\mathrm{p}}$ was the value of production of each crop (p), computed using the parameters of the modified Mitscherlich equation; $A_{p}$ was the fixed surface allocated to each crop; $\mathrm{C}_{\text {fixed }}$ were the fixed irrigation costs per unit surface; $\mathrm{C}_{\mathrm{var}}$ were the costs varying as function of the irrigation volume allocated to each crop per unit surface.

A detailed description of the optimization process, as well as of the modelling of the physical and economic constraints, has been reported in a previous paper by Rubino et al. (2008).

\section{Results and discussion}

\section{Crop growing season phenological parameters}

The quantification of the temperature effect on crop phenology by means of simple moving average and GDD technique allowed to
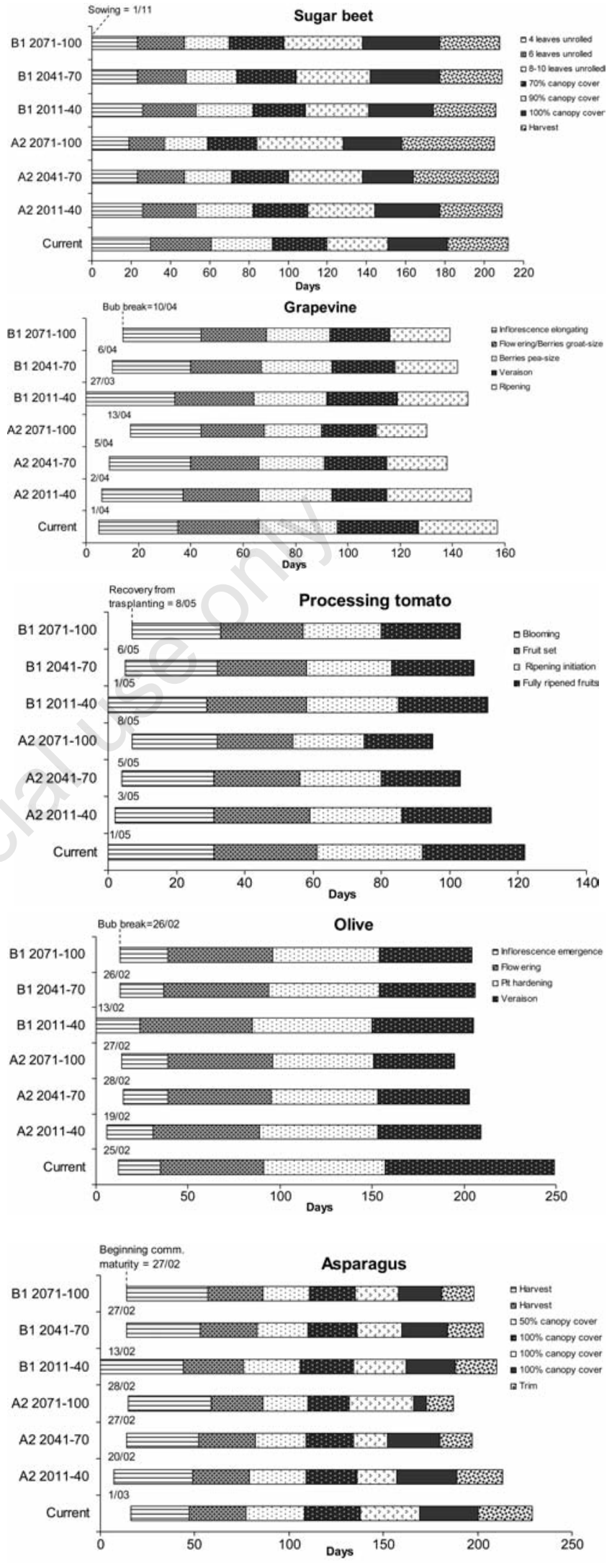

Figure 1. Growing cycle parameters under current climatic condition and future simulated scenarios for the district representative crops. Number of days on the $x$-axis is computed with respect to the climatic condition showing the earlier occurrence of the reference starting date. 
define the growing cycles phenological parameters under future climatic conditions for the five studied crops (Figure 1, a-e). Simulated climatic conditions affected crop phenological development to a different extent in relation to the species and the scenarios considered. The strongest changes were observed for A2 scenario and olive.

According to our outcomes, sugar beet cycle appeared to be only slightly affected by climate change (Figure 1a). This behaviour was attributed to the reference starting date, kept constant across current and future climatic conditions, and also to the small differences observed between current and estimated ending dates. Indeed, although individual phenological stage durations were progressively shortened, especially under A2 scenario, the total lengths of the growing season were similar (212 days for current condition against an average of 207 days for simulated scenarios) as the forecasted harvesting dates were very close to those observed under current climatic condition (Figure 1a). On the contrary, more intense modifications in the growing cycle were observed for grapevine and processing tomato. Indeed, the forecasted starting date (bud break and recovery from transplanting) was progressively delayed, causing a shift of the growing season of about 12 days (grapevine) and 1 week (processing tomato) as average of the two scenarios in the last 30 -year period (2071-2100). The end of the season was instead progressively advanced and occurred about 1 month earlier (27 days for both crops) within A2 scenario and about 20 days earlier (18 days for grapevine, 19 days for processing tomato) under B1, in the last 30-year period investigated (Figure 1, b-c). According to these predictions, total length of grapevine and processing tomato growing cycles would be shortened of 39 and 34 days under A2 scenario, of 27 and 26 days under B1.

Olive and asparagus showed similar modifications of growing cycles features, with olive being the most affected crop by the simulated climate changes (Figure 1, d-e). Although the starting dates (bud break and beginning of commercial maturity), after a slight advance recorded in the first 30 -year period, were very close to those observed under current condition, the ending dates were strongly anticipated: 54 days (A2) and 45 days (B1) for olive; 42 days (A2) and 31 days (B1) for asparagus in the last 30 -year period. If the described prediction occurred, this would lead to a reduction in the total cycle length of 41 and 29 days (A2, B1) for asparagus and of 56 and 46 days $(A 2, B 1)$ for olive by the end of the century (Figure 1, d-e).

The results obtained using the described approach confirmed common trends reported in literature. Indeed, even though the effect of climate change on crop phenology has been hypothesised under different conditions, there is an overall agreement for an earlier occurrence of key phenological events and for a consequent shortening of crop growing cycles (Moriondo and Bindi, 2007). Nevertheless, the magnitude of the shortening and the shifting of phenological stages can not be easily compared across different studies because it varies according to the time series and time intervals considered, the studied environment, the crop type and the methodology used to simulate the key phenological parameters.

\section{Yield response to irrigation under current and future climatic conditions}

The estimation of the growing cycle phenological parameters allowed to quantify, for each time period, the irrigation water requirements and thus to compare the crop yield response under current and future conditions. The parameters of the yield response function $(A$, $b, c$ and $K$ ), obtained by fitting the yield to water volumes data through the modified Mitscherlich equation, are reported in Table 3. A, which was kept constant under current and future scenarios, was expressed both as maximum yield $\left(\mathrm{t} \mathrm{ha}^{-1}\right)$ and Value of Production (VP, euro $\mathrm{ha}^{-1}$ ). Asparagus parameters, with particular regard to the maximum achievable yield $(A)$, exceeded optimum ranges. This was attributed to the reduced number of experimental data and to the behaviour of the yield-water relationship, characterised by a steep decline after optimal water requirements were overcome. Nevertheless, simulated yields fell within normal range. For this reason, as well as for the important role of asparagus in the district agricultural economy, it was decided to consider the crop in the following steps. As concerns the other crops, processing tomato showed the highest VP followed by grape (Table 3). Lower values were instead recorded for olive (5219 euro ha ${ }^{-1}$ ) and autumnal sugar beet (3564 euro ha-1) as a consequence of the current lower value of their marketable yields.

Under actual climatic conditions, $b$, indicating the amount of water available for the crop in natural conditions, varied from a maximum value of $5045 \mathrm{~m}^{3} \mathrm{ha}^{-1}$ for autumnal sugar beet to minimum values of 892 and $648.6 \mathrm{~m}^{3} \mathrm{ha}^{-1}$ for asparagus and olive, respectively (Table 3). The high value recorded for autumnal sugar beet reflected the greater potentiality of this crop to benefit from natural resources in comparison to spring-summer crops. $\mathrm{C}$, indicating the response rate of crop yield to irrigation water, ranged from $11.610^{-4}$ ha m${ }^{-3}$ for olive to 2.70 and $2.4610^{-4}$ ha m$^{-3}$ for asparagus and autumnal sugar beet. $K$, modelled only for processing tomato and asparagus, was equal to $2.7110^{-9}$ (ha $\left.\cdot \mathrm{m}^{-3}\right)^{2}$ and $29.2310^{-9}$ (ha $\left.\mathrm{m}^{-3}\right)^{2}$, respectively. These results indicated that the supply of seasonal irrigation volumes higher than those satisfying irrigation water requirements caused only slight yield decreases for processing tomato, whereas induced a steep yield decline for asparagus (Table 3).

The yield response (in terms of VP) to increasing irrigation water supply for the five studied crops, under current climatic conditions, is reported in Figure 2. From this figure, the higher Values of Production of the horticultural crops (asparagus and processing tomato), as well as the different response rate of the studied crops, immediately emerge. The Mitscherlich yield response parameters estimated for future climatic scenarios showed similar patterns in comparison to those observed under current conditions (Table 3).

With regard to the estimated natural resources availability $(b)$, a reduction was observed for processing tomato and was marked in the last thirty-year period (2071-2100) under both climate change scenarios. Specifically, $b$ decreased from $1891.1 \mathrm{~m}^{3} \mathrm{ha}^{-1}$, under current conditions, to 1697.6 and $1730.7 \mathrm{~m}^{3} \mathrm{ha}^{-1}$ for $\mathrm{A} 2$ and $\mathrm{B} 1$ respectively. A decline, across the whole period considered, but more evident under A2 scenario, was also observed for asparagus (Table 3). On the opposite, an increase in $b$ was recorded for olive, mainly under B1 scenario, corresponding to an estimated greater water availability under

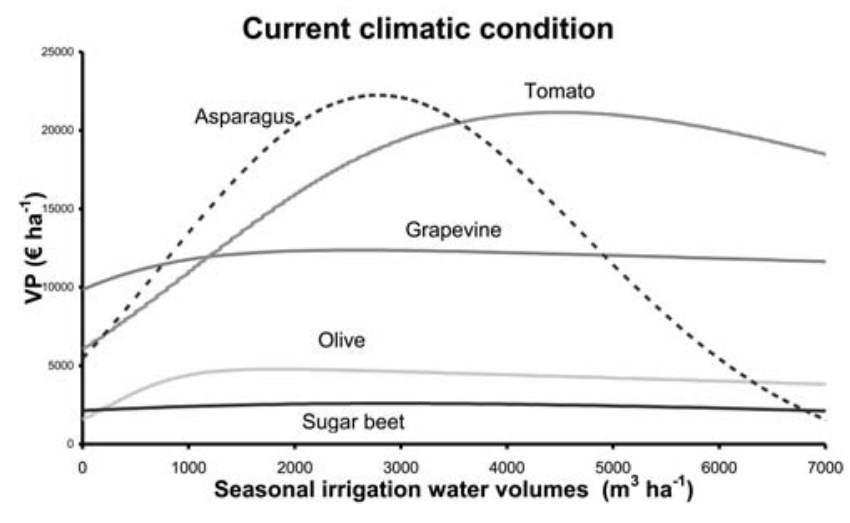

Figure 2. Yield response (value of production) for increasing seasonal irrigation water volumes under current climatic condition. 
natural conditions of $126 \mathrm{~m}^{3} \mathrm{ha}^{-1}$. Processing tomato, asparagus and grapevine showed higher $c$ values compared to the current conditions. This was observed across the entire investigated period and especially under A2 scenario. A decrease was instead found for olive with lowest values under $\mathrm{B} 1$ emission scheme. $K$ increased for both processing tomato and asparagus under A2 scenario but at a higher rate for this last crop.

\section{Optimal allocation of irrigation water at district level under current and future climatic conditions}

The non-linear mathematical optimization model written in GAMS allowed to define, for the studied district, the total irrigation water (TIW) volume which maximized the economical return, expressed as Value of Production less the fixed and variable irrigation costs (VPlic), and to identify the optimal partitioning of the irrigation water among the five crops for each class of water supply investigated. Within the range of water supply analysed $\left(10,000-7,000,000 \mathrm{~m}^{3}\right)$, the irrigation volume that maximized the economic return of the whole district surface was equal to $5,697,861 \mathrm{~m}^{3}$ and allowed a $\mathrm{VP}_{\text {lic }}$ of $29,854,000$ euros. This total water amount was partitioned among the five crops as reported in Figure 3,a. Although the greatest fraction of this volume was allocated to grapevine and secondly to olive (as they occupied the largest district surface), the seasonal volumes attributed to these crops (2561 and $1828 \mathrm{~m}^{3} \mathrm{ha}^{-1}$, respectively) corresponded to the restitution of only 59 and $50 \%$ of seasonal irrigation water requirements (Figure 4,a). Volumes equal to 85 and $100 \%$ of total irrigation water requirements (2785 and $4493 \mathrm{~m}^{3} \mathrm{ha}^{-1}$, respectively) were instead allocated to asparagus and processing tomato. A volume of $2897 \mathrm{~m}^{3} \mathrm{ha}^{-1}$, corresponding to a restitution of $54 \%$ ETc (Figure $4, \mathrm{a}$, was allocated to sugar beet. According to this optimal partitioning of the irrigation water, the TIW volume that maximized the VPlic of the whole district surface $\left(5,697,861 \mathrm{~m}^{3}\right)$ was lower than the volume necessary to fully satisfy irrigation water requirements $(100 \%$ Etc), which was equal to $9,628,453 \mathrm{~m}^{3}$. This in turn allowed a water saving on the whole surface of about $40.8 \%$. This high percentage of water saved on the whole district area was the consequence of the large surface occupied by grapevine and olive which received, under

Table 3. Parameters of Mitscherlich yield response function $(A, b, c, k)$ computed for each climatic condition considered.

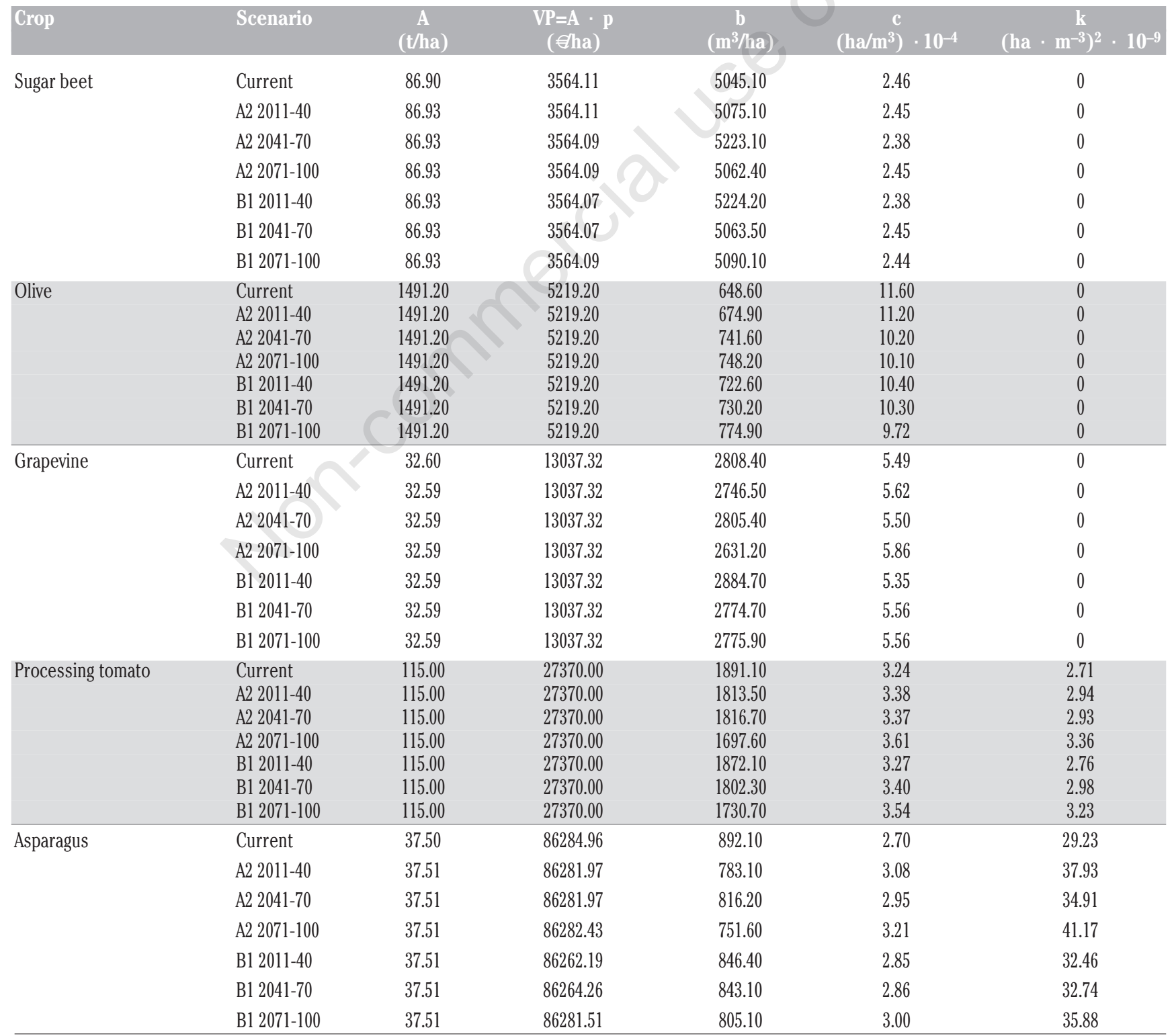


optimal conditions, seasonal volumes corresponding to about the half of the irrigation water requirements.

Interestingly, under water shortage conditions, specifically under TIW availability up to $160,000 \mathrm{~m}^{3}$ (Figure $5, \mathrm{a}$ ), the whole irrigation water was allocated to the horticultural crops (processing tomato and asparagus) with the highest volumes allocated to this last one which gave higher VP at low watering volumes (Figure 2). Indeed, only at higher TIW supplies $\left(320,000 \mathrm{~m}^{3}\right)$, when asparagus water requirements were almost satisfied, processing tomato received greater seasonal volumes and then olive groves started to be irrigated. This last
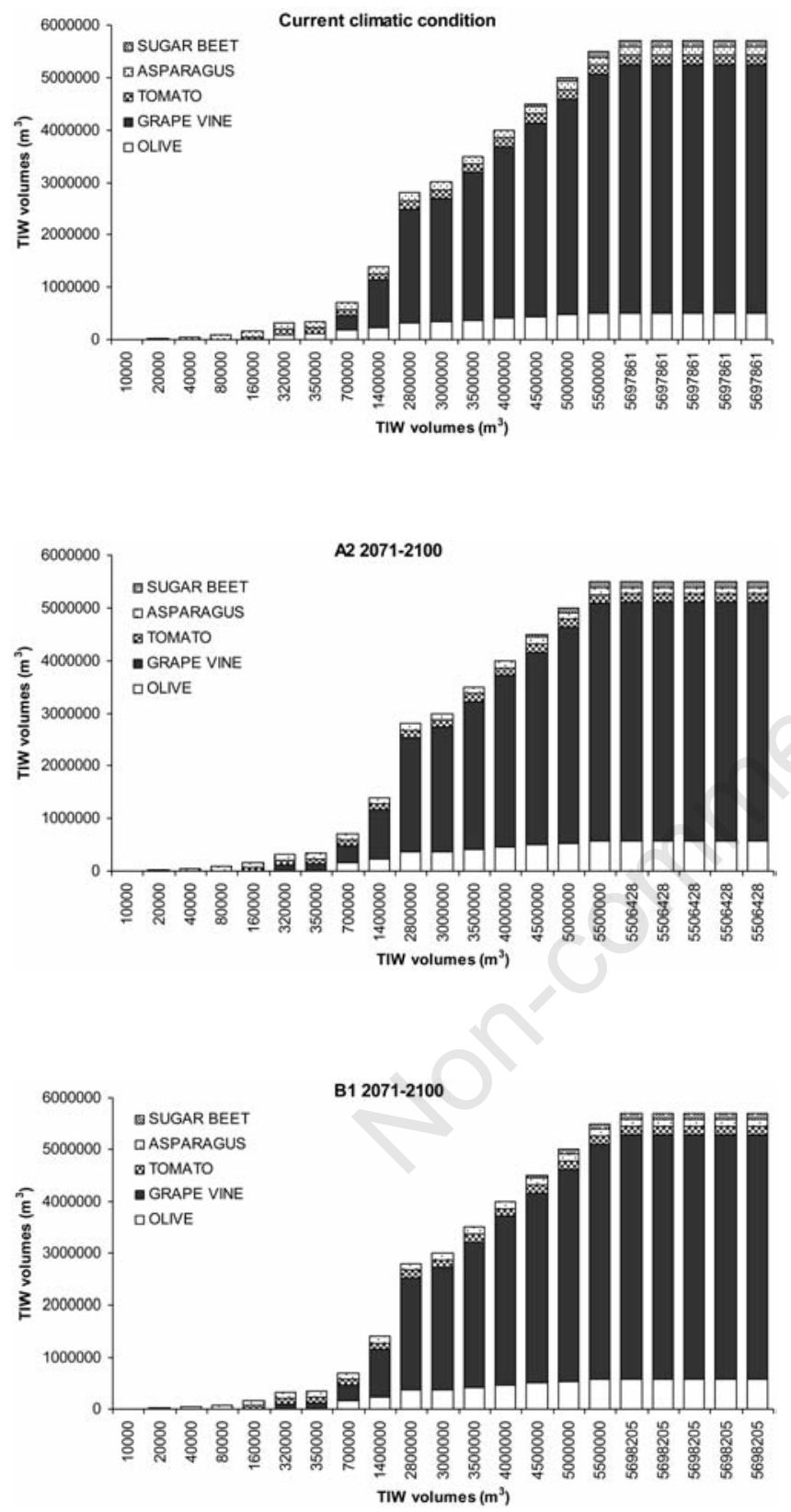

Figure 3. Optimal allocation of total irrigation water (TIW) volumes under current climatic condition (a) and future scenarios A2 2071-2100 (b), B1 2071-2100 (c). Total irrigation water volumes ranged from $10000 \mathrm{~m}^{3}$ to the volume maximizing the $\mathrm{VP}_{\text {lic }}$ (value of production less the fixed and variable irrigation costs) of the district under each climatic condition considered. crop, though characterised by a lower value of production in comparison to grapevine (Table 3), occupies indeed a lower surface. Only when total irrigation supplies were higher than $4,500,000 \mathrm{~m}^{3}$, a fraction of water started to be allocated to sugar beet (Figure 5,a).

These findings confirm previous results which have shown that, under non limiting water supplies, the highest profit may be obtained by irrigating the vegetable crops with seasonal irrigation volumes equal to $100 \%$ of the maximum evapotranspiration (Rubino et al., 2008) and allocating lower volumes to the arable crops. The total irrigation water volume that maximized the VPlic in the studied district appeared to be only slightly affected by future climatic conditions (Figure 3 and Figure 4,b-c), varying from 5,506,428 $\mathrm{m}^{3}$ (A2 scenario, period 2071-2100) to $5,814,257 \mathrm{~m}^{3}$ (B1 scenario, period 2011-2040), as consequence of the uniformity observed in the yield response parameters. The irrigation water partitioning among the five studied crops also showed similar patterns both under current and future climatic scenarios (Figures 5,b-c), so did the percentage of water saved in comparison to the actual climatic conditions (43.1 and $41.1 \%$, respectively for $\mathrm{A} 2$ and $\mathrm{B} 1$ scenarios in the 2071-2100 period).
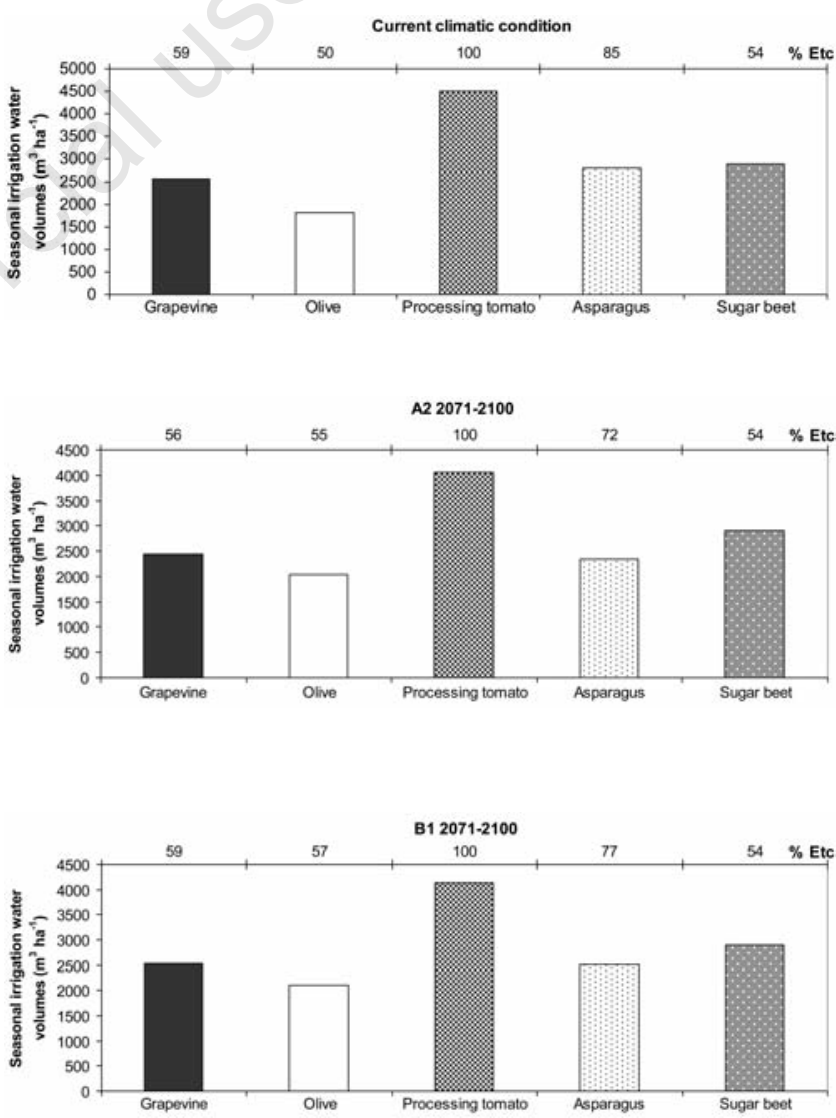

Figure 4. Seasonal irrigation water volumes $\left(\mathrm{m}^{3} \mathrm{ha}^{-1}\right)$ allocated to district representative crops within the TIW volume maximizing the $\mathrm{VP}_{\text {lic }}$ (value of production less the fixed and variable irrigation costs) under current climatic condition (a) and future scenarios: A2 2071-2100 (b), B1 2071-2100 (c). Seasonal volumes are also expressed as percentage of irrigation water requirements (\% ETc). 


\section{Conclusions}

Climate change models generally forecast an increase in average temperatures and frequency of extreme events in the Mediterranean environment by the end of this century. These changes are expected
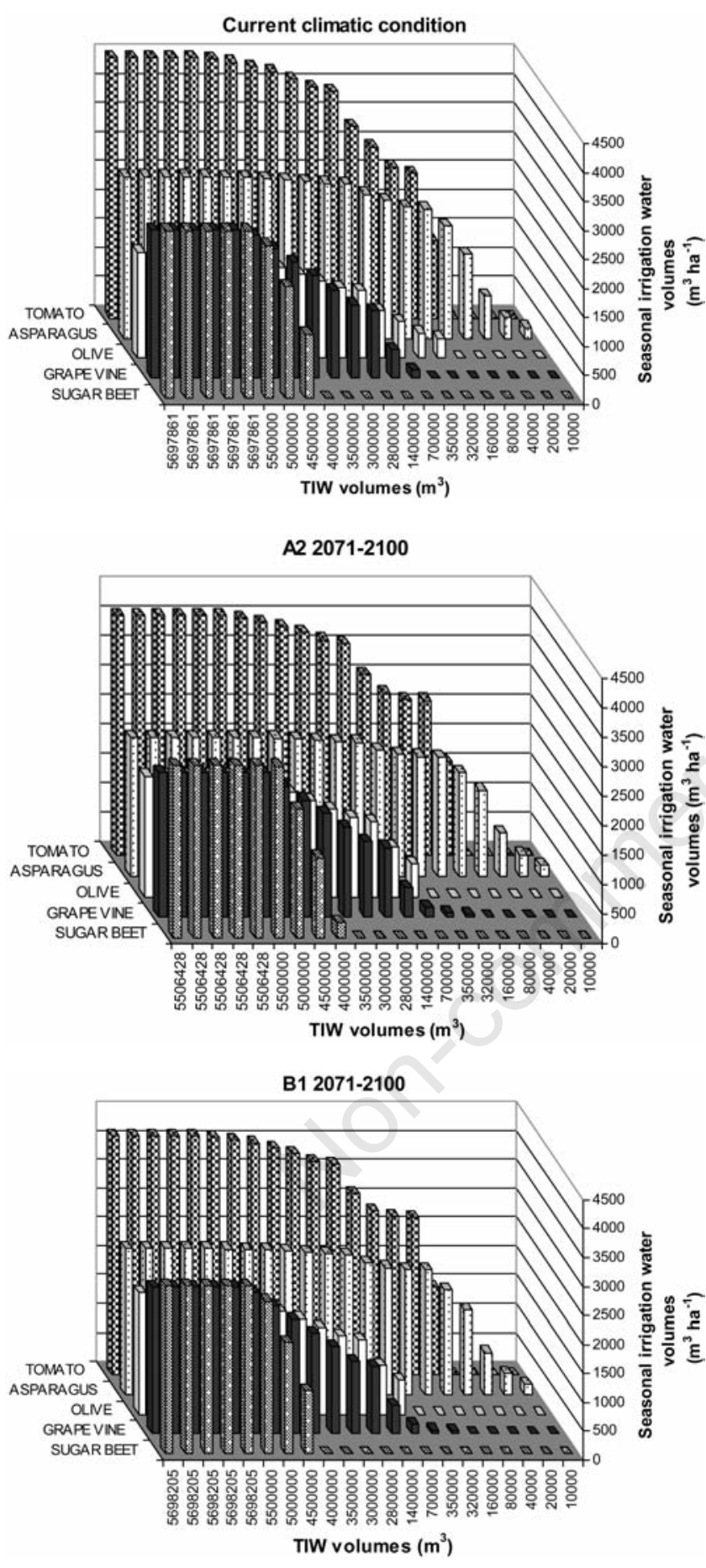

Figure 5. Seasonal irrigation water volumes $\left(\mathrm{m}^{3} \mathrm{ha}^{-1}\right)$ allocated to district representative crops under current climatic condition (a) and future scenarios: A2 2071-2100 (b), B1 2071-2100 (c). Total irrigation water (TIW) volumes ranged from $10,000 \mathrm{~m}^{3}$ to the volume maximizing the $\mathrm{VP}_{\text {lic }}$ (value of production less the fixed and variable irrigation costs) of the district under each climatic condition considered. to reduce total water availability and to have a deep impact on water use efficiency and crop phenology.

Our outcomes showed a strong effect of temperature on growing cycle parameters and crop cycle length, particularly marked for olive and under A2 scenario. This confirmed the general consensus in literature on the shortening of crop growing cycles as a consequence of forecasted temperature increase. Despite crop cycle features modifications, the irrigation water requirements and the parameters of crop yield response to irrigation were only slightly affected by the future climatic conditions in the present study. This behaviour was also attributed to the lower crop cycle length, recorded under future climatic conditions, which attenuated the differences due to the higher evapotranspirative demand. Optimal allocation of irrigation water at district level showed very similar patterns across the different climatic conditions compared, as a consequence of the similarity in crop yield response parameters.

The framework here adopted to assess water partitioning among the irrigated crops revealed to be effective in resolving the optimization problem. The total irrigation water volume that maximized the VPlic of the district under current conditions was 5,697,861 $\mathrm{m}^{3}$ and it was mainly partitioned to grapevine and olive, which occupied the largest irrigation district surface. Nevertheless, these crops received seasonal volumes corresponding only to $59 \%$ and $50 \%$ of total irrigation water requirements. On the contrary, horticultural crops, i.e. processing tomato and asparagus, received seasonal water volumes close to those fully satisfying irrigation water requirements. In addition, under water shortage conditions, within all considered climatic scenarios, the whole irrigation water was allocated to processing tomato and asparagus.

\section{References}

Al-Weshah RA, 2000. Optimal use of irrigation water in the Jordan Valley: a case study. Water Res. Manage. 14:327-338.

Ben Mechlia N, Carroll JJ, 1989. Agroclimatic modeling for the simulation of phenology, yield and quality of crop production. Int. J. Biometeorol. 33:36-51.

FA0, 2006. Water at a glance. Available from: http://www.fao.org/ $\mathrm{nr} /$ water/docs/waterataglance.pdf

Giardini L, Borin M, 1985. Proposta metodologica per l'esame delle curve di risposta produttiva all'irrigazione. Riv. Agron. 4:239-250.

Gorantiwar SD, Smout IK, 2006. Model for performance based land area and water allocation within irrigation schemes. Irrig. Drain. Syst. 20:345-360.

Hargreaves GH, Samani ZA, 1985. Reference crop evapotranspiration from temperature. Applied Eng. Agric. 1:96-99.

Howell TA, 2001. Enhancing water use efficiency in irrigated agriculture. Agron. J. 93:281-289.

Hsiao TC, Steduto P, Fereres E, 2007. A systematic and quantitative approach to improve water use efficiency in agriculture. Irrig. Sci. 25:209-231.

Intergovernmental Panel on Climate Change, 2000. Summary for Policymakers. In: N. Nakicenovic and R. Swart (eds.) IPCC Special Report Emissions Scenarios. Cambridge University Press, Cambridge, UK.

Intergovernmental Panel on Climate Change, 2007. Summary for Policymakers. In: Climate Change 2007. Cambridge University Press, Cambridge, UK.

Lamaddalena N, D’Arcangelo G, Billi A, Todorovic M, Hamdy A, Bogliotti C, Quarto A, 2004. Participatory water management in Italy: case study of the Consortium "Bonifica della Capitanata". Options Méditerranéennes Series B 48:159-169. 
Lovelli S, Perniola M, Todorovic M, 2009. Gli effetti del cambiamento climatico sulle colture. Cambiamenti climatici e risorse idriche nella regione mediterranea. Le nuove sfide per l'agricoltura. Osservatorio Permanente sul Sistema Agroalimentare dei Paesi del Mediterraneo. ISMEA Publ., Roma, Italy, pp 79-88.

Mimi ZA, Jamous SA 2010. Climate change and agricultural water demand: Impacts and adaptations. Afr. J. Environ. Sci. Technol. 4:183-191.

Moriondo M, Bindi M, 2007. Impact of climate change on the phenology of typical Mediterranean crops. Ital. J. Agrometeorol. 3:5-12.

Olesen JE, Bindi M, 2002. Consequences of climate change for European agricultural productivity, land use and policy. Eur. J. Agron. 16:239-262.

Onta PR, Loof R, Banskota M, 1995. Performance based irrigation planning under water shortage. Irrig. Drain. Syst. 9:143-162.

Paul S, Panda SN, Nagesh Kumar D, 2000. Optimal irrigation allocation: a multilevel approach. J. Irrig. Drain. E.-ASCE 126:149-156.

Pizzigalli C, Palatella L, Zampieri M, Lionello P, Miglietta MM, Paradisi P, 2012. Dynamical and statistical downscaling of precipitation and temperature in a Mediterranean area. Ital. J. Agron. $7: \mathrm{e} 2$.

Priestley CHB, Taylor RJ, 1972. On the assessment of the surface heat flux and evaporation using large-scale parameters. Mon. Weather Rev. 100:81-92.

Rana RM, Flichman G, Fratino U, Giugni M, Lamaddalena N, 2004. Un modello multicriteriale per l'allocazione ottimale della risorsa idrica. pp 463-471 in Atti XXIX Conv. Idraulica e Costruzioni Idrauliche, Trento, Italy.

Reca J, Roldan J, Alcaide M, Lopez R, Camacho E, 2001. Optimization model for water allocation in deficit irrigation systems $\mathrm{I}$. Description of the model. Agr. Water Manage. 28:103-116.

Rubino P, Catalano M, Rana R, Caliandro A, 2008. Optimal allocation of the irrigation water through a non linear mathematical model. Riv. Agron. 3:191-200.

Sahoo GB, Loof R, Abernethy CL, Kazama S, 2001. Reservoir release policy for large irrigation system. J. Irrig. Drain. E.-ASCE. 127:302-310.

Schlenker W, Hanemann W, Fisher A, 2007. Water availability, degree days and the potential impact of climate change on irrigated agriculture in California. Climatic Change 81:19-38.

Shangguan Z, Shao M, Horton R, Lei T, Qin L, Ma J, 2002. A model for regional optimal allocation of irrigation water resources under deficit irrigation and its applications. Agr. Water Manage. 52:139154. 